\title{
Canonical Correlation Analysis and a New Composite Index on Digitalization and Labor Force in the Context of the Industrial Revolution 4.0
}

\author{
Ane-Mari Androniceanu ${ }^{1}$, Irina Georgescu ${ }^{2, *}$, , Manuela Tvaronavičiene ${ }^{3}(\mathbb{C})$ and \\ Armenia Androniceanu 4 \\ 1 Doctoral School of Management, Bucharest University of Economic Studies, 6, Piata Romana, \\ 010374 Bucharest, Romania; ane.androniceanu.drd@gmail.com \\ 2 Department of Informatics and Economic Cybernetics, Bucharest University of Economics, 6, Piata Romana, \\ 010374 Bucharest, Romania \\ 3 Department of Business Economics and Management, Vilnius Gediminas Technical University 11, \\ eLT-10223 Vilnius, Lithuania; manuela.tvaronaviciene@vgtu.lt \\ 4 Department of Administration and Public Management, Bucharest University of Economics, 6, \\ Piata Romana, 010374 Bucharest, Romania; armenia.androniceanu@man.ase.ro \\ * Correspondence: irina.georgescu@csie.ase.ro
}

Received: 16 July 2020; Accepted: 18 August 2020; Published: 21 August 2020

\begin{abstract}
The current phenomenon of the economy-accelerated digitalization, known as the "Industry $4.0^{\prime \prime}$, will generate both an increased productivity, connectivity and several transformations on the labor force skills. Our research objectives are to determine the influence that digitalization has had on the workforce in several developed countries and to propose a new composite indicator that reflects these dynamics over time. We have used the Canonical Correlation Analysis (CCA) in order to identify and analyze the correlations between two sets of variables, an independent one and a dependent one. Data were collected from the World Bank and World Economic Forum for the years 2018-2019. Based on the results of our research we have determined and made a consistent analysis of the new composite index of digitalization and labor force in 19 countries. The results of our research are relevant and show not only the impact of digitalization on the labor force in different countries, but also the structural changes required by the new economic and social models. Our research can help decision-makers get in advance the necessary measures in the field of labor force in order to ensure a proper integration of these measures into the new economic model based on digitalization.
\end{abstract}

Keywords: canonical correlation analysis; digitalization; labor force; composite index

\section{Introduction}

Some of the key challenges under discussion at the World Economic Forum in Davos in January 2020 [1] have been "employment, skills and human capital", with a focus on how to generate 470 million new jobs by 2030, taking into account that the technology will fundamentally disrupt the nature of the work itself. As a result of digitization, new jobs are created and others are eliminated. An IBM survey of 1200 IT professionals and decision-makers in 13 countries indicated that two-thirds of them believe that mobile, analytics, cloud and social technologies are strategically important; however, $25 \%$ reported weak skills in each sector, and 60\% reported moderate to major deficits. Digitization produces major structural changes in all areas of economic and social life. The role of digitalization will increase in the future. Digitization is a profound phenomenon, with strong implications in all areas. The current context marked by the COVID 19 pandemic significantly influences the speed with which digitalization is integrated into economic and social systems. Thus, in many areas there are 
major structural changes, not only in the way of communication, but also the production and services processes. Digitization is leading to the adoption of digital technologies and the widespread use of technology for storing and processing, searching and transmitting information between online users. Organizations make major investments and purchase both digital products and services, as well as digital technologies relevant to specific areas of business. Economic growth and job creation change depending on the level of technological development of a country. According to the research group coordinated by Srovnalikova [2], the technology development influences online platforms enabling connections between people, changing the way people communicate and interact. The authors also think that these changes have led to the rapid growth of the sharing economy worldwide.

Over the past 50 years, the U.S. economy has experienced a steady decline in jobs involving routine manual and cognitive skills. Recent studies [3] show that $59 \%$ of the German workforce will be replaced by machines and software in the coming decades. Of the approximately 31 million people with a full or part-time job in Germany, 18 million would be laid off as a result of this technology development. Malega et al. [4] have compared the adoption of Industry 4.0 in Germany and in the Slovak Republic. The results show a logical interaction the Slovak Republic has not yet developed into a strong basis, e.g., the financial support, a situation which results in a lag in the rate of economic development in small EU countries.

Estimates of all recent prospective studies [5-8] converge to the conclusion that the Fourth Industrial Revolution will certainly lead to major changes in how value is created. Digitalization, through the third technology platform (3P)—including cloud, big data, mobile phones, cognitive computing and internet of things, will play a decisive role in the evolution of the economy and society, through the impact of the widespread adoption of these digital technologies. Due to digitization, economic growth is achieved, and the competitiveness of goods and services increases, as Shpak et al. explained [9]. The growing role of digitization in economics is influencing job profile requirements and the curriculum of lifelong learning programs. According to the World Economic Forum Report on the Future of Jobs, $65 \%$ of children entering primary school today are going to work in jobs that do not yet exist in the labor market [10]. The report indicates two major directions on labor market developments. The first is the demand for jobs in the future, predominant in the fields of science, technology, engineering, mathematics and ICT. The second is the gender difference. On the labor market this difference will deepen, as long as women avoid jobs in the technical fields. All these aspects should be known in order to reduce the shock of change caused by changes in technology. As the first three industrial revolutions demonstrated that technology has a major impact on the labor market and the business environment, we expect the current phenomenon of accelerated digitization of the economy, known as the Fourth Industrial Revolution, to have positive effects on competitiveness by increasing productivity, and bringing notable impact on the labor market, through the creation/disappearance of jobs or the emergence of completely new jobs. The creation of new business models, based on increasing connectivity, reducing communication barriers and eliminating distances, amplifies professional development factors, changes the way of adding value, leading to increased productivity. These examples are just a few arguments to explain the relevance of the topic chosen for this research.

The Internet and the digital technologies are transforming the context of our daily lives. The fact that barriers still exist in the online environment means that citizens' access to goods and services is limited. The horizon for entrepreneurs and start-ups is not very wide, and businesses and governments cannot fully benefit from digital tools. The strategy for the Digital Single Market, supported by the European Union and the measures of the OECD, displays the development of the digital economy aim to remove these barriers and create the necessary framework for the expansion of the markets. It is estimated that in the European Union, digitalization will generate an economic contribution of over 415 billion euros per year. The impact of digitalization on the labor market should not be neglected. We can say that our research based on the link between digitalization and the labor market in OECD countries is equally relevant and necessary. 
Through our paper we aim to answer an essential question: in what way and how much does digitalization influence the labor force? Our paper demonstrates how digitalization has so far influenced state economies and the labor market. The originality of our research approach consists both in highlighting and explaining the correlations between digitalization and the economic development of the 19 analyzed states, and in designing a composite indicator to determine the impact of digitalization on their labor force. We have selected a group of variables relevant to digitization and labor force. Then we have chosen appropriate research methods for discovering the correlations (Canonical Correlation Analysis) and for analyzing them (Regression Analysis). To these aspects of originality, we can add the new composite indicator named Digital and Labor Force Index designed by our research team to determine the intensity of the correlation between digitalization and its impact on the labor force in general. Then, as a premiere, we determined and analyzed this composite index in the OECD states selected in our research.

The novelty of our research is the new composite indicator designed to offer a practical tool to the state governments and business community through which they can monitor, compare and analyze the influences of digitalization on economic systems in general and on the labor force in particular. The new composite indicator proposed can be used by decision-makers or governors to design new public policies and managers to develop their business, in line with contextual changes. Based on the composite indicator designed by us, state governments can identify the necessary economic and technological measures and make the right decisions in order to support human resources integration in the labor market. Thus, they can develop efficient public policies contributing to the creation of an appropriate framework for a sustainable economic and social development.

\section{Literature Review}

The world is at the threshold of the fourth industrial revolution and this fact changes all enterprises, regardless of their sector of activity, as a research group coordinated by Shpak [11] explained in 2019. One of its most visible trends is the digital transformation. Digitization is the process of converting analog information into a digital format. In a broader context, digitalization is defined as the social transformation triggered by the massive adoption of digital technologies to generate, process and trade information. Digitization uses the collateral effects that result from their use: common platforms for application development, e-government services, e-commerce, social networking, and the availability of online information [12]. To succeed in an innovation-based economy, today's employees need a different set of skills and competences [13,14].

In countries around the world, economies are based on creativity, innovation and collaboration. Skilled jobs are more focused on solving unstructured problems and efficient analysis of information [15]. In addition, technology is replacing manual labor in most aspects of life and in most segments of the economy or, at least, is shifting communications significantly in many market segments, particularly trade [16]. Life offline becomes almost impossible. The general conclusion of the studies is that, in general, the lower one's qualification, the higher the chances of losing a job in favor of robots. Economic growth and job creation vary depending on the level of technological development of a country [17]. Other researchers [18-20] stated that employees in the service sector have a great role in increasing the rate of profit, which is the main purpose of the enterprises, to run the business smoothly, and to ensure customer satisfaction and loyalty. Digitization is one of the most visible phenomena of this decade, and its evolution is extremely fast. Manifested by the adoption of digital technologies and, respectively, the use of technology on a larger scale for storage and processing, search and retrieval of information between online users, digitalization is a profound phenomenon, with strong implications in all areas [21].

As the first three industrial revolutions demonstrated that technology has a major impact on the labor market and the business environment, we expect the current phenomenon of accelerated digitization of the economy, known as the Fourth Industrial Revolution, to have positive effects on competitiveness by increasing productivity, but also a notable impact on the labor market, through the 
creation/disappearance of jobs and the emergence of completely new occupations [22,23]. Creating new business models, based on increasing connectivity, reducing communication barriers and eliminating distances, amplifies development factors, changes the way of adding value, leading to increased productivity [24].

The new technologies and platforms offered by the tech giants have made possible the major change, in a very short time, of the mode of operation and interaction at the level of companies and authorities around the world. If before the crisis caused by COVID-19 we were talking about the digital disruption that brings unprecedented transformation and development to the way we live, work, and relate to each other, so this phenomenon changes society and the economy as a whole, with the triggering of drastic measures of social distancing. Digitization has amplified its role even more, exceeding estimates. At the same time, it has demonstrated extraordinary opportunities, making possible a lot of activities that would have been unimaginable online until the COVID-19 period. By default, this will reflect the revenue and profitability of the so-called generic digital economy, which includes tech giants, online platforms, and many other companies. It is easy to intuit that this sector will be among the few that will emerge victorious from this crisis. This will make it all the more interesting for the state budgets that will allocate huge sums to save other sectors severely affected by the crisis. It is well known that the evolution of digital technologies, in combination with other essential generic technologies, leads to a change in the way related products and services are designed, produced and marketed, as well as in the way in which value is generated from them. Technological advances-such as the Internet of Things (IoT), 5G technology, cloud computing, data analytics and robotics-are transforming products, processes and business models in all sectors, ultimately creating new industrial patterns.

The transformations generated by digitalization have an impact on all job categories, not just repetitive ones. The impact refers especially to the creation of new jobs for both current employees and future generations, jobs that will certainly require different skills than those we develop today [25]. In our paper we analyze the impact of digitalization on the workforce in 2018-2019 in 19 OECD countries and show how a new composite indicator, named by us the Digital and Labor Force Index, reflects this mutual influence. The main determining factors that must be taken into account are the following:

(1) The increasing computing power of computer systems that allows the analysis of data in real time, in the context of large volumes of data;

(2) Continuous improvement of the methods of processing and use of large volumes of data, crucial for markets and innovation;

(3) The creation of new products and services;

(4) Accelerating the speed of innovation;

(5) New models of artificial intelligence, possible due to the growth in computing power, which will support harmonious cooperation between humans and robots. The algorithms will focus on profiling different types of users, and if an individual's action does not correspond to its historical behavior, it will be notified immediately. Machine learning systems can generate false alarms, so human intervention is needed to make the decision to retrain certain algorithms. New generative manufacturing processes, such as 3D printing, allow for savings. The physical world and the digital world are getting closer, resulting in the fusion of physical-cybernetic systems (CPS4), such as generative manufacturing processes. 3D printing, for example, allows a digital model to be transformed into a physical product. The interaction between the two identities of CPS — physical and digital—endows products with innovative functions, capable of continuous expansion throughout their life cycle;

(6) The role of human intervention changes from a skilled worker to a supervisor of services available in the network; 
(7) The augmentation in connectivity, determined by the enormous boost in the volume of data of the last decade;

(8) A new class of suppliers will intensify their competition in the future. An example is Google, which becomes a player in the car market, through its contribution to the development of autonomous vehicles. Large Japanese companies (Canon, Sharp), as well as some Western companies have based their long-term program innovation for obtaining economic performance on knowledge generation. Japanese companies, which excel in the process of production innovation, have focused on exploiting "tacit" knowledge within the company (internal knowledge that has been accumulated through the company's experience and which is difficult to transmit in the form of information). These companies have motivated and stimulated human resources to generate new knowledge by accepting courageous visions of products and economic strategy, coupled with an organization mentality that promotes transparency and knowledge dissemination [26]. A modern organization should be trainable, its employees should continually learn and reflect. Therefore, it is necessary to adapt the workforce to the new specific requirements of knowledge-based management and innovation in the context of digitalization. The positive effects of digital infrastructure on productivity are manifested indirectly, through changes in the following areas:

- Labor. It will be healthier and with a higher level of qualification, due to improved access to basic services such as sanitation, education and healthcare;

- Creativity and innovation. These effects are becoming more and more essential, so business owners try to retain specialists on ICT, to change the channels of communications with customers, widening digital ones, in face of new challenges and new possibilities of ICT development [27]. Nanosensors and the Internet of Things could have an impact on medicine, architecture, agriculture and drug manufacturing. Autonomous electric vehicles can save lives, reduce pollution, increase savings and improve the quality of life. Smart digital assistants will soon help people in a wide range of daily tasks. Optogenetics can be directed deeper into the brain, and can help treat brain disorders. The engineering of metabolic systems allows the manufacture of chemical compounds that underlie life in a more efficient and cheaper way by using plants. By adopting digital technology, companies can increase their efficiency, reduce costs and streamline relationships with customers, employees and business partners. In the current international economic context, we notice that the economic model is changing. Thus, new collaborative economic models are developed [28]. These changes are determined by a variety of factors and variables that state governments and the business environment should consider. The Fourth Industrial Revolution is expected to have significant effects on capital and the labor market, including by changing the way we interact and even the behavior of individuals [29]. The increasing use of physical and cyber systems (CPS) is not reduced to Industry 4.0 itself, having a considerable social impact. With digitalization, productivity improves, some jobs are replaced by technology, and labor-intensive tasks are relocated to emerging markets, where labor is cheaper. Another effect of digitization is the increase in relocation. As companies in advanced countries improve their productivity due to digitalization, they transfer their jobs to less developed countries, with a lower degree of digitalization. Digitization also has effects on labor mobility, facilitating the combination of work and private life. In principle, mobile forms of work can be advantageous for employees and employers alike. In addition to the opportunities offered by the digital age, there are also risks: an increased concentration of data in the hands of a few economic monopolies, an intensification of the digital divide and the polarization of society, upgrading the importance of training. The old business world was characterized by predictable environments in which the focus was on predicting and optimizing results. In the current context, business is based on knowledge as a strategic 
asset. The business environment is marked by uncertainty and a limited ability to anticipate the future. Therefore, in the context of the knowledge-based society, the generation of knowledge should be the object of investments. A series of papers published in recent years [30,31] demonstrate a strong link between the generation of knowledge and the process of innovation of products and services in the context of the digital society. In fact, there is a direct and intrinsic relationship between knowledge, innovation and digitalization. Our study is focused on digitalization and its impact on the workforce, but at the micro level, the transformation of the economic models, based on an efficient management of knowledge and innovation. In our work we analyzed the process and how much digitalization influences the labor force in selected countries using canonical correlation analysis and regression and we proposed a composite index that measures this influence in 19 OECD countries in the period analyzed. This composite indicator reflects over time the dynamics of the labor force on the national, regional or international market in the context of the accelerated digitization of socio-economic systems.

\section{Research Results and Analysis}

In the first part of this section we have undertaken the research using Canonical Correlation Analysis (CCA). Based on the results obtained and the indicators in the databases, we developed a composite index called the Index of Digitization and Labor Force (DLFI). With its help we determined the impact of digitalization on labor force productivity in the 19 states included in our analysis. Data have been collected from the World Bank [32] and World Economic Forum [33] and the latest available were for the years 2018-2019. The 19 states included in this research are Argentina, Australia, Brazil, Canada, China, France, Germany, India, Indonesia, Italy, Japan, Mexico, Russia, Saudi Arabia, South Africa, South Korea, Turkey, Great Britain and USA.

\subsection{Canonical Correlation Analysis}

Canonical Correlation Analysis was introduced by Hotelling [34] as a modelling method to identify and analyze the associations between two sets of variables, an independent one and a dependent one. CCA is useful when there are multiple correlations between outcome variables. Pairs of canonical variates are built as orthogonal linear combinations of the variables in the two initial sets, that explain best the inter- and intra-set variability [35]. The number of dimensions is equal to the number of elements in the smaller set. The first canonical correlation has the highest importance in interpretation between any predictor and any outcome variable. The structure coefficients are significant when their absolute values are above 0.45 .

CCA was applied on the set of 19 OECD countries and 10 indicators following the line of Georgescu and Kinnunen [36]. As it can be seen in Table 1, the digitalization indicators $\left(V_{1}-V_{5}\right)$ represent the independent set and the labor force indicators $\left(V_{6}-V_{10}\right)$ represent the dependent set.

Table 1. The main research variables.

\begin{tabular}{ccc}
\hline Variable & Variable Label & Source \\
\hline$V_{1}$ & Individuals using the Internet (\% of population) & World Bank \\
$V_{2}$ & Research and development expenditure (\% of GDP) & World Bank \\
$V_{3}$ & Human Capital Index & World Bank \\
$V_{4}$ & Secure Internet servers per million people & World Economic Forum (WEF) \\
$V_{5}$ & Mobile cellular subscriptions & WEF \\
$V_{6}$ & Total labor force & World Bank \\
$V_{7}$ & GDP per capita (PPP current international \$) & World Bank \\
$V_{8}$ & GINI index & WEF \\
$V_{9}$ & Total unemployment (\% of total labor force) & World Bank \\
$V_{10}$ & Net foreign direct investment (thousands) & World Bank \\
\hline
\end{tabular}

(Source: Our selection based on the World Bank and World Economic Forum databases). 
The goal of CCA is to predict five variables: Total labor force, GDP per capita (PPP current international USD), GINI index, Total unemployment, Net foreign direct investment, based on five independent variables: Individuals using the Internet, Research and development expenditure, Human Capital Index, Secure Internet servers per million people, and Mobile cellular subscriptions. We used the data collected from the World Bank and World Economic Forum for the years 2018-2019. We work with standardized variables. Figure 1 describes the distributions of digitalization indicators from set 1 and the correlations within set 1 . The within-correlations range from $-0.598\left(V_{1}\right.$ Individuals using the Internet vs. $V_{5}$ Mobile cellular subscriptions) to 0.8 ( $V_{1}$ Individuals using the Internet vs. $V_{3}$ Human Capital Index).

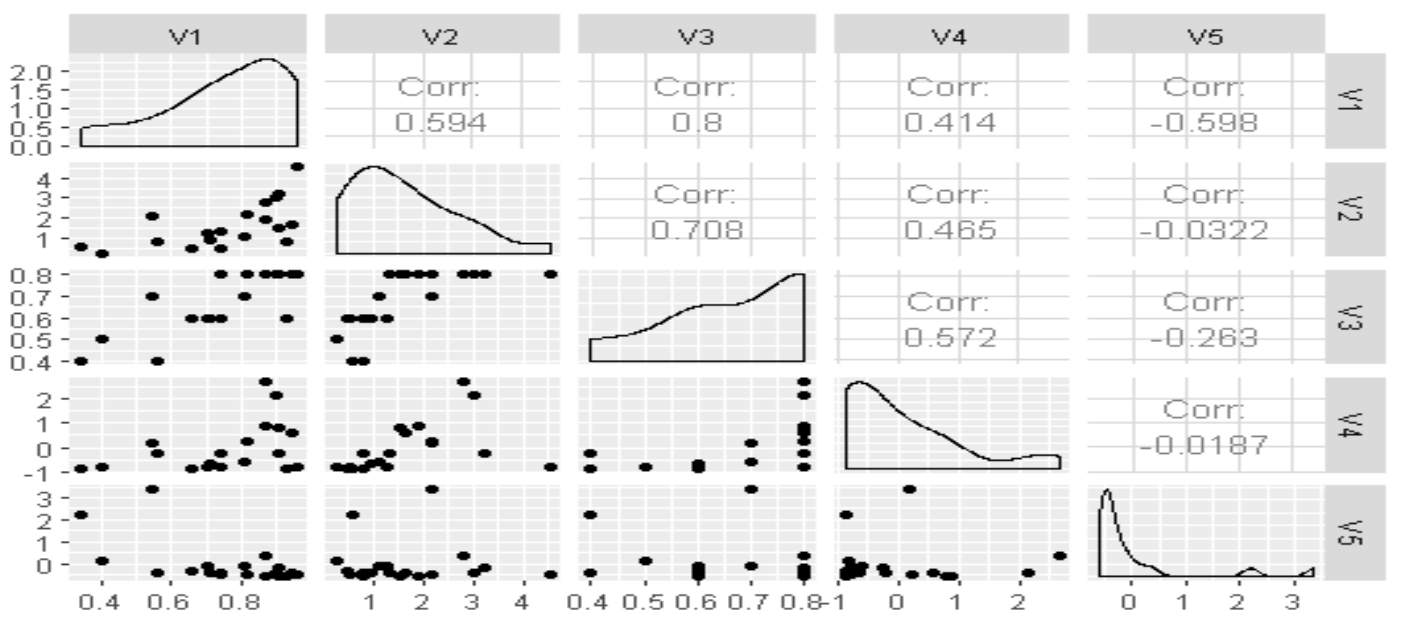

Figure 1. Set 1 Digitalization variables (Source: our determination).

Figure 2 describes the distributions of labor force indicators from set 2 and the correlations within set 2. The within-correlations range from $-0.759\left(V_{7}\right.$ GDP per capita vs. $V_{8}$ Gini index) to $0.477\left(V_{8}\right.$ Gini index vs. $V_{9}$ Total unemployment).

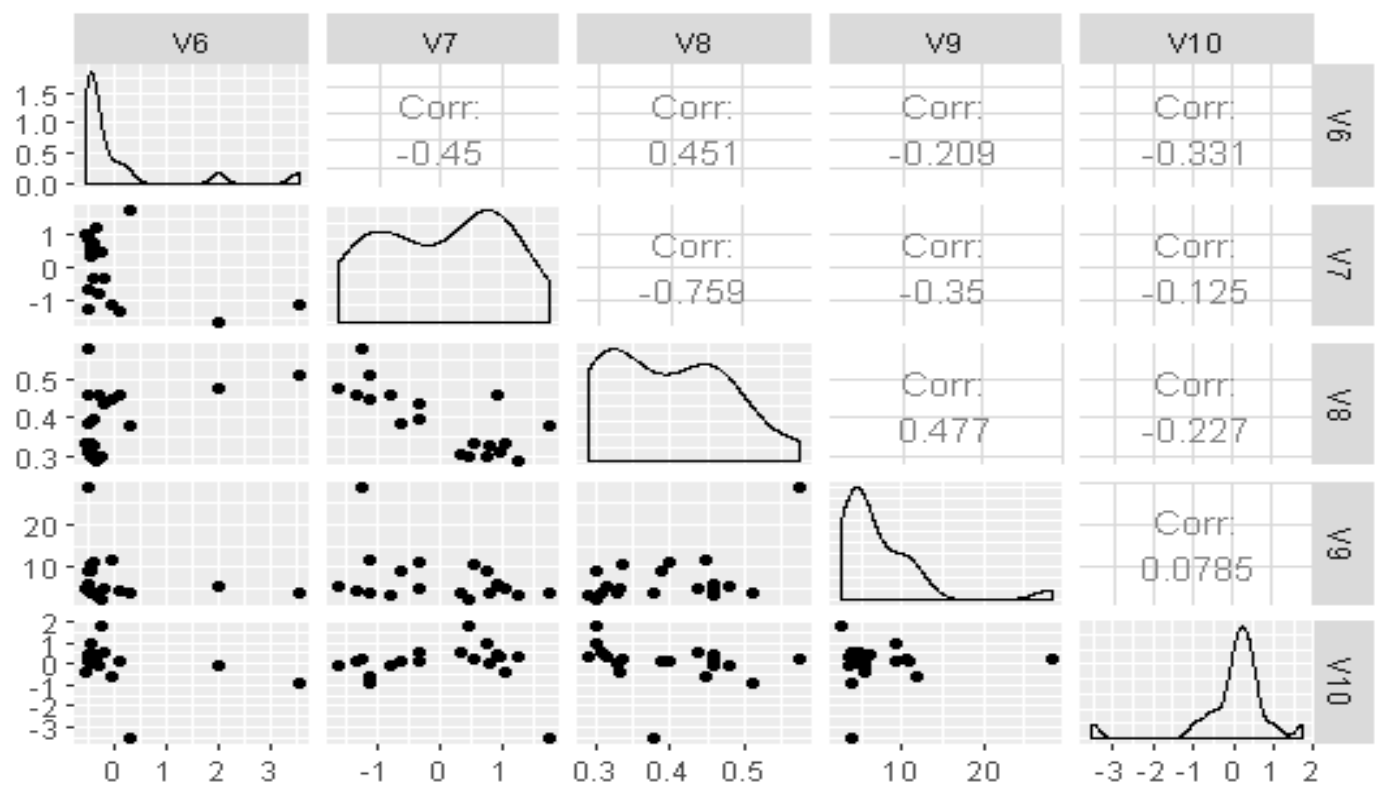

Figure 2. Set 2: Labor force indicators. (Source: our determination). 
The positive correlation between GINI index and total unemployment is consistent with economic theory since when unemployment rate decreases, GINI index will also decrease. Penha Cysne in 2009 [37] gives a theoretical proof (Proposition 3) of the positive relation between unemployment and GINI index of income distribution. The authors prove that both indicators are increasing functions of the probability of lay-off and the probability that a worker does not get a job offer; accordingly, when any of these probabilities increases, there is a positive relation between unemployment rate and GINI index. Several studies on CCA have been conducted by Dattalo [38] and Gonzales et al. [39]. By applying CCA, we determined the number of canonical variables significant in explaining the dependence between the two sets, digitalization and labor force indicators.

\subsection{CCA Model}

We denote here the independent set $X=\left(V_{1}, \ldots, V_{5}\right)^{T}$ and the dependent set $Y=\left(V_{6}, \ldots, V_{10}\right)^{T}$. There are the five pairs of canonical variates of the model below. $A_{i}$ can be written as a linear combination of the elements of set $X$ and $B_{i}$ as a linear combination of elements of set $Y$ as follows:

$$
\begin{aligned}
& A_{1}=a_{11} V_{1}+\ldots+a_{15} V_{5} \\
& \ldots \\
& A_{5}=a_{51} V_{1}+\ldots+a_{55} V_{5} \\
& B_{1}=b_{11} V_{6}+\ldots+b_{15} V_{10} \\
& \ldots \\
& B_{5}=b_{51} V_{6}+\ldots+b_{55} V_{10}
\end{aligned}
$$

The canonical correlation for the $i$ th canonical pair $\left(A_{i}, B_{i}\right)$ is the correlation between $A_{i}$ and $B_{i}$ : $\rho_{i}^{*}=\frac{\operatorname{cov}\left(A_{i}, B_{i}\right)}{\sqrt{\operatorname{var}\left(A_{i}\right) \operatorname{var}\left(B_{i}\right)}}, i=1, \ldots, 5$.

The aim of CCA is to find the linear combination that maximizes the canonical correlation $\rho_{i}^{*}$ for the canonical pairs $\left(A_{i}, B_{i}\right), i=1, \ldots, 5$.

The main steps of CCA are:

(i) To determine if there is any relationship between the two sets of variables. By Wilks lambda, we reject the null hypothesis that there is no relationship between the two sets and conclude that they are dependent;

(ii) The null hypothesis from above is equivalent to the null hypothesis that all five canonical variate pairs are not correlated: $H_{0}: \rho_{1^{*}}=\ldots=\rho_{5^{*}}=0$. Wilks lambda is significant and the canonical correlations are in a decreasing order, therefore we conclude that at least $\rho_{1 *} \neq 0$. Successively we find that the first two canonical pairs are correlated and the other three are not;

(iii) To interpret each canonical variable, we compute the correlation between each variable and the corresponding canonical variate;

(iv) Finally we find the best predictors for each variable in the dependent set.

The first step of CCA is to discover whether there is any relationship between the two sets $X$ and $Y$. For this one considers a multivariate multiple regression model, where one predicts the labor force indicators (set $Y$ ) from the digitalization indicators (set $X$ ). We have five multiple regression equations, each one predicting one of $Y$ variables from the five variables in set $X$ :

$$
\begin{aligned}
& V_{6}=\beta_{10}+\beta_{11} V_{1}+\beta_{12} V_{2}+\beta_{13} V_{3}+\beta_{14} V_{4}+\beta_{15} V_{5} \\
& \cdots \\
& V_{10}=\beta_{50}+\beta_{51} V_{1}+\beta_{52} V_{2}+\beta_{53} V_{3}+\beta_{54} V_{4}+\beta_{55} V_{5}
\end{aligned}
$$


We test the null hypothesis that the regression coefficients from above are equal to 0 , which is equivalent to testing that the two sets of indicators $\mathrm{X}$ and $\mathrm{Y}$ are independent.

$$
H_{0}: \beta_{i j}=0, i, j=1, \ldots, 5
$$

Pillai's trace test, Hotelling's trace test, and Wilk's lambda multivariate criteria are significant, with $p<0.05$. All tests in Table 2 prove that there is a statistically significant and positive linear relationship between the dimensions of digital competitiveness and labor force indicators.

Table 2. Multivariate tests of significance $(S=5, M=-1 / 2, N=31 / 2)$.

\begin{tabular}{cccccc}
\hline Test Name & Value & Approx. F & Hypoth. DF & Error DF & Sig. of F \\
\hline Pillais & 2.80259 & 3.31650 & 25 & 65 & 0.000 \\
Hotellings & 234.11658 & 69.29851 & 25 & 37 & 0.000 \\
Wilks & 0.00013 & 13.98758 & 25 & 34.94 & 0.000 \\
Roys & 0.99555 & & & & \\
\hline
\end{tabular}

(Source: our calculation).

The CCA analysis generated five roots, as they can be seen in Table 3. The roots rank the eigenvalues in a decreasing order.

Table 3. Eigenvalues and canonical correlations.

\begin{tabular}{cccccc}
\hline Root No. & Eigenvalue & Pct. & Cum. Pct. & Canon Cor. & Sq. Cor. \\
\hline 1 & 223.6426 & 95.52617 & 95.52617 & 0.99777 & 0.99555 \\
2 & 8.76312 & 3.74306 & 99.26923 & 0.94740 & 0.89757 \\
3 & 1.18436 & 0.50589 & 99.77512 & 0.73634 & 0.54220 \\
4 & 0.48323 & 0.20640 & 99.98152 & 0.57078 & 0.32579 \\
5 & 0.04327 & 0.01848 & 100 & 0.20364 & 0.04147 \\
\hline
\end{tabular}

The eigenvalue can be computed as the ratio between the corresponding squared correlation and one minus the squared correlation, for example the largest eigenvalue 223.64 can be computed as $223.64=\frac{0.995}{1-0.995}$. Canonical correlations represent Pearson correlations of the pairs of canonical variates. The first canonical correlation, 0.99777 represents the correlation coefficient between the first pair of canonical variates. Squared canonical correlations of the canonical variate pairs are interpreted as $R^{2}$ from linear regression. Namely, $99.55 \%$ of the variation in $A_{1}$ is explained by the variation in $B_{1} ; 89.75 \%$ of the variation in $A_{2}$ is explained by the variation in $B_{2}$ etc. These values are very high, suggesting that the first two canonical correlations are the most significant. In Table 4, we test the null hypothesis that all correlations associated with the roots are equal to 0 . The above hypothesis $H_{0}$ is equivalent to the null hypothesis that all pairs of canonical variates are not correlated:

$$
H_{0}: \rho_{1^{*}}=\ldots=\rho_{5^{*}}=0
$$

Since Wilks lambda is significant and the canonical correlations are decreasingly ordered, we can say that at least $\rho_{1 *} \neq 0$. Next, we test the hypothesis that the remaining pairs of canonical variates are correlated:

$$
H_{0}: \rho_{2^{*}}=\ldots=\rho_{5^{*}}=0 .
$$

Since $p<0.05$, we conclude that the second canonical variate pair is correlated, $\rho_{2} \neq 0$. 
Table 4. Dimension reduction analysis.

\begin{tabular}{cccccc}
\hline Roots & Wilks L. & F & Hypoth. DF & Error DF & Sig. of F \\
\hline 1 to 5 & 0.00013 & 13.98758 & 25 & 34.94 & 0.000 \\
2 to 5 & 0.03030 & 4.17312 & 16 & 31.19 & 0.000 \\
3 to 5 & 0.29585 & 1.94261 & 9 & 26.92 & 0.088 \\
4 to 5 & 0.64625 & 1.46367 & 4 & 24 & 0.244 \\
5 to 5 & 0.95853 & 0.56245 & 1 & 13 & 0.467 \\
\hline
\end{tabular}

(Source: our calculation).

The last three tests are not significant, since $p>0.05$.

As it can be seen in Figure 3, the first canonical variate for labor force is plotted against the first canonical variate for digitalization. The regression line shows a good fit of the model.

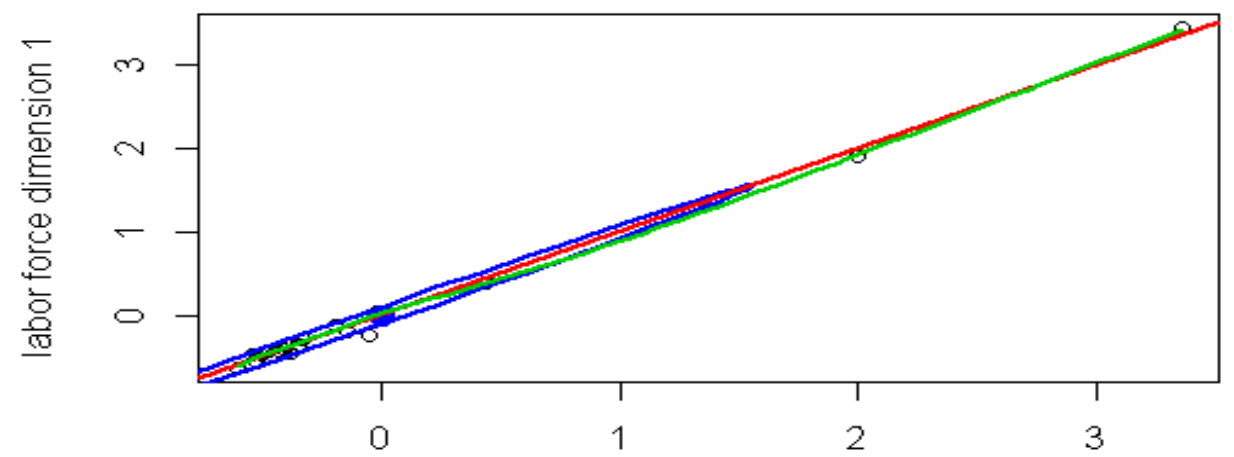

Figure 3. The regression line on digitalization and labor force (Source: our determination).

Next we have determined the raw and standardized canonical coefficients for the dependent variables in Tables 5 and 6.

Table 5. Raw canonical coefficients for DEPENDENT variables.

\begin{tabular}{cccccc}
\hline Variable & $\mathbf{1}$ & $\mathbf{2}$ & $\mathbf{3}$ & $\mathbf{4}$ & $\mathbf{5}$ \\
\hline$V_{6}$ & 0.99705 & -0.43549 & 0.20062 & 0.00148 & 0.85893 \\
$V_{7}$ & 0.05800 & -0.81598 & -1.03995 & 0.98320 & 0.76682 \\
$V_{8}$ & -0.07574 & 4.39837 & -16.86318 & 16.03492 & -1.52472 \\
$V_{9}$ & -0.00276 & -0.01628 & -0.00337 & -0.13749 & 0.18350 \\
$V_{10}$ & 0.00100 & 0.15409 & 0.16337 & 1.00245 & 0.69076 \\
\hline
\end{tabular}

(Source: our calculation).

Table 6. Standardized canonical coefficients for DEPENDENT variables.

\begin{tabular}{cccccc}
\hline Variable & $\mathbf{1}$ & $\mathbf{2}$ & $\mathbf{3}$ & $\mathbf{4}$ & $\mathbf{5}$ \\
\hline$V_{6}$ & 1.02437 & -0.44743 & 0.20612 & 0.00152 & 0.08247 \\
$V_{7}$ & 0.05959 & -0.83834 & -1.06845 & 1.01015 & -0.78783 \\
$V_{8}$ & -0.00636 & 0.36953 & -1.41676 & 1.34718 & -0.12880 \\
$V_{9}$ & -0.01635 & -0.09636 & -0.01995 & -0.81362 & 1.08589 \\
$V_{10}$ & 0.00102 & 0.15831 & 0.16337 & 1.02982 & 0.70969 \\
\hline
\end{tabular}

(Source: our calculation).

The raw canonical coefficients are interpreted as in the linear regression models, considering the canonical variates as outcome variables. For example, a one-unit augmentation in variable $V_{6}$ total labor force leads to a 0.997 increase in the first variate of labor force measurement (Table 5). The standardized canonical coefficients are analyzed with respect to scaled variables with mean zero and standard deviation 1 . For example, an increase in one standard deviation in variable $V_{6}$ (total labor 
force) leads to a 1.02437 standard deviation increase in the first variate of labor force measurement (Table 6).

Using the coefficient values in the first column of Table 5, the first canonical variable for labor force can be written:

$$
B_{1}=0.99705 V_{6}+0.058 V_{7}-0.07574 V_{8}-0.00276 V_{9}+0.001 V_{10}
$$

In the above interpretation, the magnitude of the coefficients gives the contribution of the variables to the canonical variable. The magnitude also depends on the variances of the variables; the data standardization (Table 6) has no impact on the canonical correlation.

Looking at the first canonical variable for labor force (Table 7) we can see it is strongly dominated by $V_{6}$ total labor force, with a Pearson correlation coefficient 0.99775 . The second canonical variable for labor force is strongly negatively dominated by $V_{7}$ GDP per capita with a Pearson correlation coefficient -0.90355 . For the remaining canonical variables for labor force, none of the correlations are sufficiently large, therefore, these canonical variables yield little information about the data. The correlations below are significant when their absolute values are above 0.45 .

Table 7. Correlations between DEPENDENT and canonical variables.

\begin{tabular}{cccccc}
\hline Variable & $\mathbf{1}$ & $\mathbf{2}$ & $\mathbf{3}$ & $\mathbf{4}$ & $\mathbf{5}$ \\
\hline$V_{6}$ & 0.99775 & 0.06438 & -0.00383 & -0.01616 & 0.00856 \\
$V_{7}$ & -0.39102 & -0.90355 & -0.10007 & 0.14255 & 0.01891 \\
$V_{8}$ & 0.40271 & 0.72197 & -0.56043 & -0.04041 & 0.02956 \\
$V_{9}$ & -0.25395 & 0.47197 & -0.35194 & -0.44372 & 0.62066 \\
$V_{10}$ & -0.34593 & 0.32024 & 0.55319 & 0.53348 & 0.43310 \\
\hline
\end{tabular}

(Source: our calculation).

In Table $8,29.886 \%$ of the variance among a dependent set labor force is explained by the first dependent canonical variate, while $29.75 \%$ is explained by the first covariate canonical variate. Similarly, $33.47 \%$ of the variance among labor force is explained by the second dependent canonical variate, while $30.04 \%$ is explained by the second covariate canonical variable.

Table 8. Variance in DEPENDENT explained by canonical variables.

\begin{tabular}{ccccc}
\hline CAN. VAR. & Pct Var DEP & Cum Pct DEP & Pct Var COV & Cum Pct COV \\
\hline 1 & 29.88649 & 29.88649 & 29.75345 & 29.75345 \\
\hline 2 & 33.47723 & 63.36421 & 30.04873 & 59.80217 \\
\hline 3 & 15.07980 & 78.44401 & 8.17628 & 67.97845 \\
\hline 4 & 10.07397 & 88.51798 & 3.28205 & 71.26050 \\
5 & 11.48202 & 100 & 0.47617 & 71.73666 \\
\hline
\end{tabular}

(Source: our calculation).

Next we have determined the raw and standardized canonical coefficients for the covariates in Tables 9 and 10.

A one-unit increase in variable $V_{1}$ (Individuals using the Internet) leads to a 0.2255 augmentation in the first variate of digitalization measurements (Table 9). An increase of one standard deviation in variable $V_{1}$ (Individuals using the internet) leads to a 0.04153 standard deviation increase in the first variate of digitalization measurements (Table 10). The first canonical variable for digitalization can be written:

$$
A_{1}=0.22554 V_{1}-0.01884 V_{2}+0.54108 V_{8}-0.00339 V_{4}+1.01252 V_{5}
$$

The correlations from Table 11 show the relative contribution of each covariate to each canonical variable. 
Table 9. Raw canonical coefficients for COVARIATES.

\begin{tabular}{cccccc}
\hline Covariate & $\mathbf{1}$ & $\mathbf{2}$ & $\mathbf{3}$ & $\mathbf{4}$ & $\mathbf{5}$ \\
\hline$V_{1}$ & 0.22554 & 1.85924 & 7.89360 & 9.50161 & 2.57324 \\
$V_{2}$ & -0.01884 & 0.02800 & 0.49354 & -0.45117 & 1.18492 \\
$V_{3}$ & 0.54108 & -3.14261 & 10.60657 & -1.35379 & -9.89297 \\
$V_{4}$ & -0.00339 & -0.46073 & -0.80737 & -0.76823 & -0.03193 \\
$V_{5}$ & 1.01252 & -0.24418 & -0.48460 & 0.91086 & -0.02546 \\
\hline
\end{tabular}

(Source: our calculation).

Table 10. Standardized canonical coefficients for COVARIATES.

\begin{tabular}{cccccc}
\hline Covariate & $\mathbf{1}$ & $\mathbf{2}$ & $\mathbf{3}$ & $\mathbf{4}$ & $\mathbf{5}$ \\
\hline$V_{1}$ & 0.04153 & -0.34239 & -1.45365 & 1.74978 & 0.47388 \\
\hline$V_{2}$ & -0.02112 & 0.03139 & 0.55322 & -0.50573 & 1.32821 \\
\hline$V_{3}$ & 0.07562 & -0.43920 & 1.48235 & -0.18920 & -1.38262 \\
\hline$V_{4}$ & -0.00348 & -0.47336 & -0.82949 & -0.78928 & -0.03281 \\
$V_{5}$ & 1.04026 & -0.25087 & -0.49787 & 0.93582 & -0.02616 \\
\hline \multicolumn{7}{c}{ (Source: our calculation). }
\end{tabular}

Table 11. Correlations between COVARIATES and canonical variables.

\begin{tabular}{cccccc}
\hline Covariate & $\mathbf{1}$ & $\mathbf{2}$ & $\mathbf{3}$ & $\mathbf{4}$ & $\mathbf{5}$ \\
\hline$V_{1}$ & -0.53364 & -0.72082 & 0.01491 & 0.41235 & 0.15935 \\
$V_{2}$ & 0.02191 & -0.69463 & 0.36903 & 0.00301 & 0.61710 \\
$V_{3}$ & -0.18136 & -0.89571 & 0.36752 & 0.15489 & -0.07582 \\
$V_{4}$ & 0.02769 & -0.84695 & -0.31625 & -0.42637 & -0.01016 \\
$V_{5}$ & 0.99632 & 0.07696 & -0.02088 & -0.02909 & 0.01164 \\
\hline
\end{tabular}

Looking at the first canonical variable for digitization (Table 11) we can see it is strongly dominated by $V_{5}$ (Mobile cellular subscriptions) with a Pearson correlation coefficient 0.99632 . The second canonical variable for digitization is strongly negatively dominated by $V_{1}$ (Individuals using the Internet), $V_{2}$ (Research and development expenditure), $V_{3}$ (Human Capital Index) and $V_{4}$ (Secure Internet servers). For the remaining canonical variables for digitization, none of the correlations are sufficiently large, therefore, these canonical variables yield little information about the data. The correlations are significant when their absolute values are above 0.45 .

In Table 12, 26.11\% of the variance among the covariate set digitalization is explained by the first dependent canonical variate, while $26.23 \%$ of the variance is explained by the first covariate canonical variate.

Table 12. Variance in COVARIATES explained by canonical variables.

\begin{tabular}{ccccc}
\hline CAN. VAR. & Pct Var DEP & Cum Pct DEP & Pct Var COV & Cum Pct COV \\
\hline 1 & 26.11471 & 26.11471 & 26.23148 & 26.23148 \\
2 & 45.37479 & 71.48949 & 50.55271 & 76.78419 \\
3 & 4.03324 & 75.52273 & 7.43865 & 84.22284 \\
4 & 2.45435 & 77.97708 & 7.53342 & 91.75625 \\
5 & 0.34187 & 78.31896 & 8.24375 & 100 \\
\hline
\end{tabular}

(Source: our calculation). 
Similarly, $45.37 \%$ of the variance among digitalization is explained by the second dependent canonical variate, while $50.55 \%$ is explained by the second covariate canonical variate.

In Table 13, one can see the regression analysis results of the effect of the digitalization indicators on each work force indicator. Beta value measures the importance of each covariate.

Table 13. Regression analysis for WITHIN CELLS error term: individual univariate.

\begin{tabular}{|c|c|c|c|c|c|c|c|}
\hline \multicolumn{8}{|c|}{ Dependent Variable $V_{6}$} \\
\hline Covariate & B & Beta & Std. Err. & t-Value & Sig. of $t$ & Lower $-95 \%$ & CL-Upper \\
\hline$V_{1}$ & 0.0516 & 0.0092 & 0.2598 & -0.1986 & 0.846 & -0.5096 & 0.6129 \\
\hline$V_{2}$ & -0.0125 & -0.0136 & 0.0277 & -0.4526 & 0.658 & -0.0724 & 0.0473 \\
\hline$V_{3}$ & 0.3208 & 0.0436 & 0.3037 & 1.0526 & 0.31 & -0.3352 & 0.977 \\
\hline$V_{4}$ & -0.0227 & -0.0227 & 0.0245 & -0.9267 & 0.371 & -0.0758 & 0.0303 \\
\hline$V_{5}$ & 1.0130 & 1.013 & 0.0298 & 33.9212 & 0 & 0.9485 & 1.0775 \\
\hline \multicolumn{8}{|c|}{ Dependent Variable $V_{7}$} \\
\hline Covariate & B & Beta & Std. Err. & t-Value & Sig. of $\mathbf{t}$ & Lower $-95 \%$ & CL-Upper \\
\hline$V_{1}$ & 2.9468 & 0.5282 & 1.1661 & 2.5269 & 0.025 & 0.4275 & 5.4662 \\
\hline$V_{2}$ & -0.0874 & -0.0954 & 0.1244 & -0.703 & 0.494 & -0.3562 & 0.1813 \\
\hline$V_{3}$ & 1.5914 & 0.2165 & 1.3622 & 1.1675 & 0.264 & -1.3534 & 4.5368 \\
\hline$V_{4}$ & 0.4033 & 0.4033 & 0.1102 & 3.6572 & 0.003 & 0.165 & 0.6416 \\
\hline$V_{5}$ & -0.0783 & -0.0783 & 0.1340 & -0.5846 & 0.569 & -0.3679 & 0.2112 \\
\hline \multicolumn{8}{|c|}{ Dependent Variable $V_{8}$} \\
\hline Covariate & B & Beta & Std. Err. & t-Value & Sig. of $t$ & Lower -95\% & CL-Upper \\
\hline$V_{1}$ & 0.1573 & 0.3449 & 0.1328 & 1.184 & 0.258 & -0.1297 & 0.4443 \\
\hline$V_{2}$ & -0.0146 & -0.1956 & 0.0141 & -1.0344 & 0.320 & -0.0452 & 0.0159 \\
\hline$V_{3}$ & -0.5324 & -0.8857 & 0.1553 & -3.4277 & 0.004 & -0.868 & -0.1968 \\
\hline$V_{4}$ & 0.0028 & 0.0351 & 0.0125 & 0.2286 & 0.823 & -0.0242 & 0.03 \\
\hline$V_{5}$ & 0.0351 & 0.4301 & 0.0125 & 2.3028 & 0.038 & 0.0021 & 0.068 \\
\hline \multicolumn{8}{|c|}{ Dependent Variable $V_{9}$} \\
\hline Covariate & B & Beta & Std. Err. & t-Value & Sig. of $\mathbf{t}$ & Lower $-95 \%$ & CL-Upper \\
\hline$V_{1}$ & -5.5427 & -0.1724 & 15.9782 & -0.3468 & 0.734 & -40.0616 & 29.9761 \\
\hline$V_{2}$ & 0.9090 & 0.1721 & 1.7047 & 0.5332 & 0.603 & -2.7739 & 4.592 \\
\hline$V_{3}$ & -30.8878 & -0.7294 & 18.6788 & -1.6536 & 0.112 & -71.241 & 9.4652 \\
\hline$V_{4}$ & 1.1331 & 0.1967 & 1.511 & 0.7498 & 0.467 & -2.1314 & 4.3976 \\
\hline$V_{5}$ & -2.8150 & -0.4887 & 1.8366 & -1.5327 & 0.149 & -6.7288 & 1.1527 \\
\hline \multicolumn{8}{|c|}{ Dependent Variable $V_{10}$} \\
\hline Covariate & B & Beta & Std. Err. & t-Value & Sig. of $\mathbf{t}$ & Lower -95\% & CL-Upper \\
\hline$V_{1}$ & -0.7516 & -0.1357 & 2.6281 & -0.288 & 0.778 & -6.435 & 4.9207 \\
\hline$V_{2}$ & 0.1881 & 0.2053 & 0.2804 & 0.671 & 0.514 & -0.4176 & 0.7939 \\
\hline$V_{3}$ & 1.9477 & 0.2649 & 3.0724 & 0.6339 & 0.537 & -4.6897 & 8.5853 \\
\hline$V_{4}$ & -0.7235 & -0.7235 & 0.2485 & -2.9109 & 0.012 & -1.2605 & -0.1865 \\
\hline$V_{5}$ & -0.3547 & -0.3547 & 0.3021 & -1.1741 & 0.261 & -1.0073 & 0.2979 \\
\hline
\end{tabular}

(Source: our calculation).

Based on the calculations above, we reach the following conclusions:

- The effect of $V_{5}$ (Mobile cellular subscriptions) is more important than the effect of $V_{3}$ (Human Capital Index) when predicting $V_{6}$ (Total labor force).

- The effect of $V_{1}$ (Individuals using the Internet) is more important than the effect of $V_{4}$ (Secure Internet servers) when predicting $V_{7}$ (GDP per capita).

- The effect of $V_{3}$ (Human Capital Index) is more important in absolute value than the effect of $V_{5}$ (Mobile cellular subscriptions) when predicting $V_{8}$ (GINI index).

- The effect of $V_{3}$ (Human Capital Index) is more important in absolute value than the effect of $V_{5}$ (Mobile cellular subscriptions) when predicting $V_{9}$ (Total unemployment). 
- The effect of $V_{4}$ (Secure Internet servers) is more important in absolute value than the effect of $V_{5}$ (Mobile cellular subscriptions) when predicting $V_{10}$ (Net foreign direct investment).

3.3. A New Composite Index Named Digital and Labor Force Index for Measuring the Correlation between Labor Force and Digitalization

Following OECD methodology [40,41] and Georgescu and Kinnunen [36] we will build a composite indicator containing the two datasets, digitalization and work force indicators. The purpose of the composite indicator is to make simpler comparisons of the 19 countries in order to illustrate complex problems such as the impact of digitalization on labor force. First we apply principal component analysis (PCA), according to Jolliffe [42] and retain a number of principal components according to a specific criterion. Kaiser-Meyer-Olkin test has the value $0.703>0.5$, meaning that PCA is suitable for this dataset. Bartlett's test of sphericity has the value 0 (less than 0.05 ) indicating that a factor analysis is suitable.

According to Table 14, to obtain a good representation of the original data, we apply the variance-explained criterion and we retain three principal components which explain $85.245 \%$ of the total variance.

Table 14. Rotated Component Matrix and Total Variance Explained.

\begin{tabular}{|c|c|c|c|c|c|c|c|}
\hline \multicolumn{4}{|c|}{ Rotated Component Matrix } & \multicolumn{4}{|c|}{ Total Variance Explained } \\
\hline & \multicolumn{3}{|c|}{ Component } & \multirow{2}{*}{ Component } & \multicolumn{3}{|c|}{ Rotation Sums of Squared Loadings } \\
\hline & 1 & 2 & 3 & & Total & $\%$ of Variance & Cumulative \% \\
\hline$V_{1}$ & 0.722 & -0.571 & 0.116 & 1 & 4.020 & 40.201 & 40.201 \\
\hline$V_{2}$ & 0.789 & 0.015 & 0.141 & 2 & 2.822 & 28.221 & 68.422 \\
\hline$V_{3}$ & 0.907 & -0.206 & 0.189 & 3 & 1.682 & 16.822 & 85.245 \\
\hline$V_{4}$ & 0.468 & -0.083 & 0.801 & & & & \\
\hline$V_{5}$ & -0.109 & 0.969 & 0.122 & & & & \\
\hline$V_{6}$ & -0.093 & 0.968 & 0.117 & & & & \\
\hline$V_{7}$ & 0.740 & -0.458 & 0.400 & & & & \\
\hline$V_{8}$ & -0.856 & 0.368 & 0.052 & & & & \\
\hline$V_{9}$ & -0.724 & -0.386 & 0.089 & & & & \\
\hline$V_{10}$ & 0.099 & -0.277 & -0.879 & & & & \\
\hline
\end{tabular}

(Source: our calculation).

Then, we build a compound index denoted by PC whose coefficients are computed as the ratios between the proportion of the variance explained by each component and their total explained variance:

$$
\mathrm{PC}=\frac{40.202}{85.245} P C_{1}+\frac{28.221}{85.245} P C_{2}+\frac{16.882}{85.245} P C_{3}
$$

The elements of the PC vector are computed as the ratios above multiplied by the loadings corresponding to each variable found in the component matrix (Table 14). For example, the coefficient of PC representing $V_{1}$ (Individuals using the Internet) is calculated as:

$$
\frac{40.202}{85.245} \times 0.722+\frac{28.221}{85.245} \times(-0.571)+\frac{16.882}{85.245} \times 0.116=0.174438
$$

The composite index denoted here by DLFI will have the form:

DLFI $=0.174438 \times$ Individuals using the Internet $+0.404986 \times$ Research and development expenditure $+0.396978 \times$ Human Capital Index $+0.351864 \times$ Secure Internet servers per million people $+0.293551 \times$ Mobile cellular subscriptions $+0.299775 \times$ Total labor force $+0.27658 \times$ GDP per capita $+(-0.23196) \times$ GINI index $+(-0.4516) \times$ Total unemployment $+(-0.21909) \times$ Net foreign direct investments. 
The composite index DLFI is built with standardized data. Its values will be rescaled to the interval (0-100) by using the min-max normalization formula [43,44]:

$$
z_{i}=\frac{x_{i}-\min (x)}{\max (x)-\min (x)}
$$

where $x=\left(x_{1}, \ldots, x_{n}\right)$ and $z_{i}$ is the $i$ th normalized data.

In Figure 4, the Bar Chart Composite Index for the 19 countries is presented.

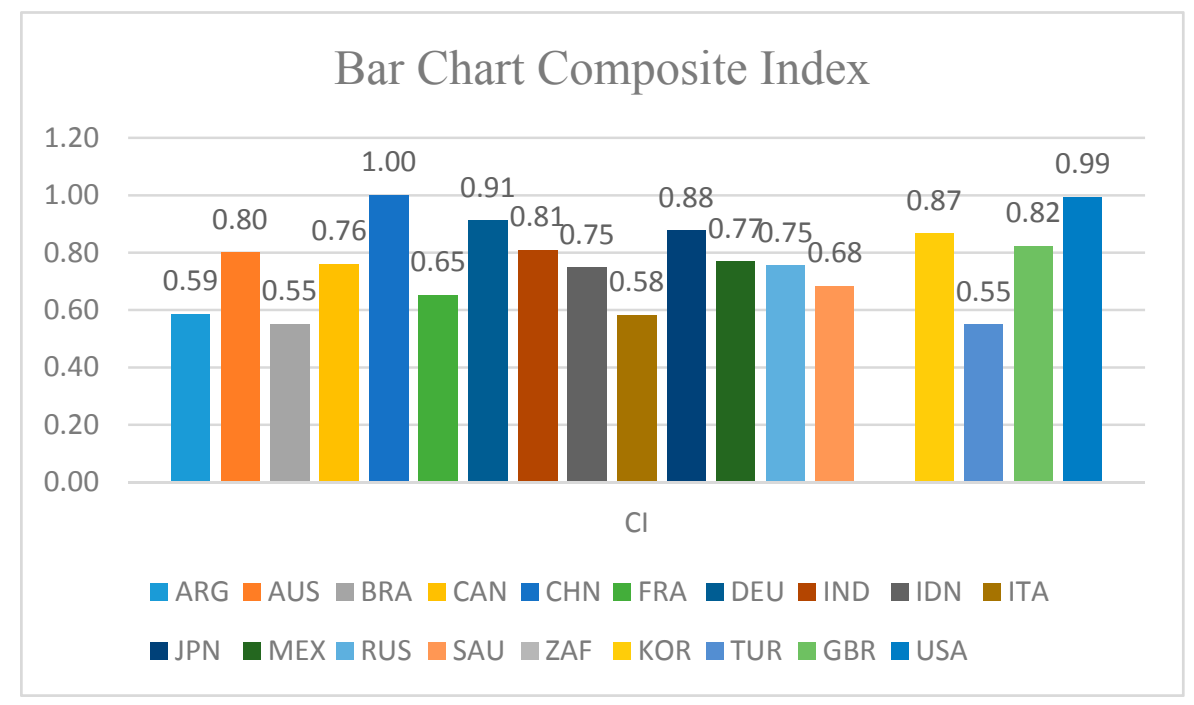

Figure 4. The Index of Digitalization and Labor Force. (Source: based on our calculation).

In the group of 19 developed countries, China takes the first place (DLFI = 1), followed by United States (DLFI $=0.99$ ) and Germany (DLFI $=0.91)$. China's top position in this ranking is due to its being among the global leaders in some key digital industries. According to [45], some of these key digital industries are e-commerce, where China holds over $40 \%$ of global transactions, penetrating into US market by $10 \%$, followed by fintech. China's consumption relative to mobile payments by individuals amounts to 790 billion USD in 2016 [46], 11 times more than US. A report of the European Investment Bank from 2020 [45] shows that many digital technology companies are located in China or US. In EU, digital adoption rate is smaller than in US; the same report [45] shows that $66 \%$ of the manufacturing companies from EU and $78 \%$ of the US companies have adopted at least one technology. Germany ranks third because the adoption rate for German robotics, 3D and virtual reality technologies is above EU and US average [46]. For the manufacturing companies, Germany is above EU average in adopting digital technology. In this ranking, South Africa occupies the last position because manufacturing companies lack advanced factory automation and high connectivity. According to Harvard Business Review [47], six countries from different African regions distinguish themselves with respect to how digital technology drives economic development: Egypt, Ethiopia, Kenya, Rwanda, Nigeria and South Africa. South Africa is seen as the regional leader in digital jobs creation, having a favorable environment and regulations that encourage digital business. According to Chakravorti and Chaturvedi (2019) South Africa has 64\% internet penetration and internet and mobile speed below the global median [47].

Usually composite indicators are measured with productivity growth, here described by GDP per capita. This composite indicator representation by means of GDP per capita helps assess the positions of countries with respect to labor force and digitalization competitiveness (Figure 5). 


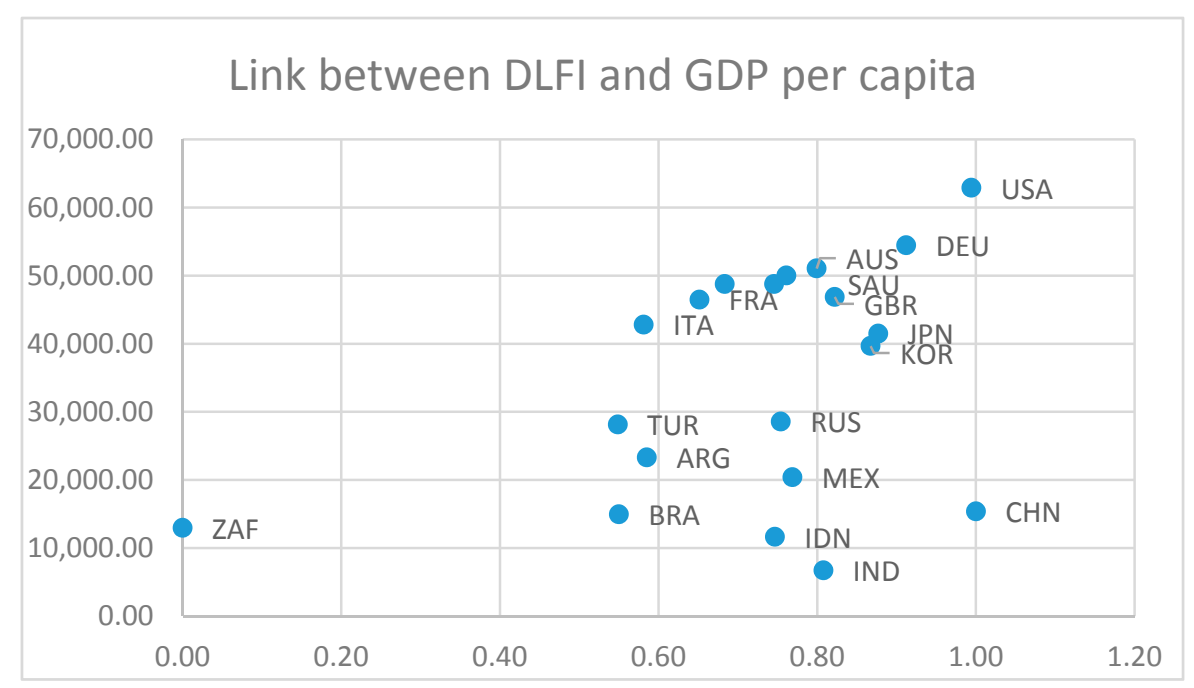

Figure 5. The representation of the Index of Digitalization and Labor Force and the GDP per capita of the 19 countries (Source: our determination).

As we can see, the high digitalized countries are expected to have high GDP per capita. South Africa is an outlier, having the smallest value of DLFI and a GDP per capita of USD 12,938.40. On the same map, USA and Germany are in a close position due to their similarities pointed out above.

\subsection{Limitations and Future Research}

The main limitations of our research are as follows:

- The relatively small number of variables integrated in the analysis. A significant number of digitalization indicators and their larger diversity would lead to a more substantial and consistent research study. At the same time, a larger number of labor force indicators would offer a more complete image of labor market dynamics and would give the opportunity to develop a multidimensional analysis of the labor market.

- The small number of states included in the research The Composite Index of Digitalization and Labor Force computed for a larger number of states would facilitate the comparisons among them and would be a basis for more representative research.

- The relatively short period of time we analyzed. This aspect can be extended by means of timeseries analysis: moving average, exponential smoothing, autoregressive moving average etc.

These limitations are also due to the lack of complete databases required in our analysis.

In our future research we will include several states and we will significantly increase the number of variables based on which we will determine the composite indexes for each state. In addition, in the future we want to make a comparative analysis between states taking into account the value of indexes for digitization and the labor force established by us through this research. Moreover, we will extend this subject by determining a representative aggregate indicator for digitalization and labor force.

\section{Conclusions}

Canonical Correlation Analysis was performed on 19 countries for the period 2018-2019 using a set of five indicators for labor force and another set of five indicators for digitalization. Direct links were determined from the second set to the first set. Canonical correlations showed strong links from mobile cellular subscriptions and Human Capital Index to total labor force, GINI index and total unemployment. The CCA test showed that the first two pairs of canonical variates are correlated. The first canonical variable for labor force is strongly dominated by total labor force, while the first canonical variable for digitalization is strongly dominated by individuals using the internet. 
In the same line as our research, the research group coordinated by Rastegar [48] applies Canonical Correlation Analysis to study the interactions between the pillars of technological readiness and the labor market efficiency. The technological readiness measures the rapidity with which an economy adopts the latest technology and includes indices such as firm-level technology absorption, foreign direct investments and technology transfers, internet access, broadband internet subscriptions and internet bandwidth. The labor market efficiency refers to the flexibility to shift workers from an activity to another at low cost [48] and to ensure incentives for workers and contains indices among which are flexibility of wage-determination, pay and productivity, redundancy costs, and ratio of women to men in the labor force. Sima at al. [49] conducted an analysis on 111 studies and identified the drivers for human capital development, such as new skills: productivity, digitalization, innovations, internet users, in the context on industrial revolution 4.0. As we demonstrated with our research, these drivers contribute to the development of human capital. Rosin and a research team [50] demonstrated that a high degree of digitalization in new joint ventures contributes to a greater operational efficiency and cost reductions. Through our research we have shown that, in addition, digitalization contributes to increasing labor productivity.

Jandrić and Randelović [51] applied Principal Component Analysis, cluster analysis and latent class cluster analysis to evaluate the skills adaptability of work force in 30 European countries. They classified the countries in terms of adaptability in three clusters: high performing (North and Western Europe), medium performing (Central Europe and Baltic countries), and respectively, low performing (South and South-Eastern Europe). From this perspective, our research has highlighted the fact that digitalization requires a major adaptation of human resources training. As we have shown in our research, digitalization will determine not only the change of the content of some activities, but also the creation of new jobs on the labor market.

The results of our research are interesting and relevant both theoretically and practically. From a theoretical point of view, the creation of a composite index to determine the impact of digitalization on the labor force is a novelty in the field of knowledge. This index can be used by other researchers in their work. From a practical point of view, our work offers a management tool for all those who are involved in the decision-making process, both in government structures and in private organizations. In our paper, we have shown that digitization is necessary and will cover most areas of activity in which human resources work. Based on the results of our research, the necessary decisions can be made both to support the expansion of digitalization, but also to have the human resources with the necessary skills for a massive integration on the labor market in the digital age.

The experience of the first three industrial revolutions has shown that technology has a major impact on the labor market, in some areas leading to the disappearance of jobs, and in others to the emergence of completely new occupations and business opportunities [52,53]. The possible consequences of the digitalization of the economy for the creation and disappearance of jobs differ depending on the time frame considered. In the short term, we are talking about the disappearance of jobs, because robots can take over tasks such as repetitive, dangerous or physically tiring jobs, but also the emergence of new jobs, related to the adoption of new technologies [54,55]. In the medium and long term, we can talk about the modernization of qualifications, but also about a possible polarization of qualifications, which could result in new forms of unskilled work. The balance of job creation and abolition appears positive. Thus, a 10\% increase in the degree of digitization would lead to a $1.02 \%$ decrease in the unemployment rate. The greatest effect is felt in the emerging economies of East Asia, South Asia and Latin America, which benefit from a total of over 4 million jobs created as a result of the digitalization of these regions. On the other hand, job creation in economies at an advanced stage of development, such as North America and Western Europe, is estimated to be more modest. Our research shows that highly digitalized countries have a better GDP per capita, mainly because their labor force productivity is higher than the others [56]. This correlation is demonstrated by the new composite index. The Index of Digitalization and the Labor Force proposed by us helps researchers and the state governments determine the intensity of such correlation [57]. Our research in 
19 countries demonstrates that, based on such determinations, government policies can influence the digitization process and training of the workforce in different domains [58] significantly in order to achieve high labor productivity and an effective integration of the labor force with the labor market.

Author Contributions: Conceptualization: A.-M.A., I.G., M.T. and A.A.; methodology: I.G.; Software: I.G.; Validation: A.-M.A., I.G., M.T. and A.A.; Formal analysis: I.G.; Investigation: A.-M.A.; Resources: all authors; Data curation: I.G.; Writing—original draft preparation: A.-M.A., I.G., M.T. and A.A.; writing-review and editing: I.G.; Visualization: A.-M.A.; Supervision: M.T. and A.A. All authors have read and agreed to the published version of the manuscript.

Funding: This research received no external funding.

Acknowledgments: We have the administrative and technical support of the International Centre for Public Management. We would like to thank both reviews for their useful comments and suggestions and to Anca Mariana Pegulescu for the final proof-reading of our paper.

Conflicts of Interest: The authors declare no conflict of interest.

\section{References}

1. World Economic Forum. Technology Can Be a Great Ally in the Drive for Greater Inclusion and Diversity. Available online: https://www.weforum.org/ (accessed on 11 June 2020).

2. Srovnalíková, P.; Semionovaitè, E.; Baranskaitè, E.; Labanauskaitè, D. Evaluation of the impact of sharing economy on hotel business. J. Tour. Serv. 2020, 20, 150-169. [CrossRef]

3. Susskind, R.E.; Susskind, D. The Future of the Professions: How Technology Will Transform the Work of Human Experts; Oxford University Press: Cambridge, UK, 2015.

4. Malega, P.; Rudy, V.; Kovac, J.; Kovac, J. The competitive market map as the basis for an evaluation of the competitiveness of the Slovak republic on an international scale. J. Compet. 2019, 11, 103-119. [CrossRef]

5. Georgescu, I.; Kinnunen, J. The Digital Effectiveness on Economic Inequality: A Computational Approach. In Business Revolution in A Digital Era; Dima, A.M., D’Ascenzo, F., Eds.; Springer: Berlin, Germany, 2020; forthcoming.

6. Androniceanu, A.; Kinnunen, J.; Georgescu, I.; Androniceanu, A.-M. Multidimensional analysis of consumer behaviour on the european digital market. In Perspectives on Consumer Behaviour, Contributions to Management Science; Sroka, W., Ed.; Springer Nature Switzerland AG: Singapore, 2020; pp. 75-95, Print ISBN: 978-3-030-47379-2. [CrossRef]

7. Androniceanu, A.; Georgescu, I.; Kinnunen, J. Digitalization Clusters within the European Union. In Proceedings of the Education Excellence and Innovation Management through Vision 2020, Granada, Spain, 10-11 April 2019; Soliman, K.S., Ed.; pp. 1719-1729.

8. Kinnunen, J.; Androniceanu, A.; Georgescu, I. Digitalization of EU Countries: A Clusterwise Analysis. In Proceedings of the International Management Conference, Bucharest, Romania, 31 October-1 November 2019; Volume 13, pp. 1-12.

9. Shpak, N.; Kuzmin, O.; Dvulit, Z.; Onysenko, T.; Sroka, W. Digitalization of the marketing activities of enterprises: Case study. Information 2020, 11, 109. [CrossRef]

10. World Economic Forum. The Future of Jobs Report 2018. Geneva. pp. vii-xix. Available online: http: //www3.weforum.org/docs/WEF_Future_of_Jobs_2018.pdf (accessed on 20 May 2020).

11. Shpak, N.; Odrekhivskyi, M.; Doroshkevych, K.; Sroka, W. Simulation of innovative systems under industry 4.0 conditions. Soc. Sci. 2019, 8, 202. [CrossRef]

12. Westerlund, M. Digitalization, internationalization and scaling of online SMEs. Technol. Innov. Manag. Rev. 2020, 10, 48-57. [CrossRef]

13. Žul'ová, J.; Švec, M.; Madleňák, A. Personality aspects of the employee and their exploration from the GDPR perspective. Cent. Eur. J. Labour Law Pers. Manag. 2018, 1, 68-77. [CrossRef]

14. Dzwigol, H.; Dzwigol-Barosz, M.; Miskiewicz, R.; Kwilinski, A. Manager competency assessment model in the conditions of Industry 4.0. Entrep. Sustain. Issues 2020, 7, 2630-2644. [CrossRef]

15. Kotarba, M. Measuring digitalization, key metrics. Found. Manag. 2017, 9, 123-138. [CrossRef]

16. Victor, V.; Thoppan, J.J.; Fekete-Farkas, M.; Grabara, J. Pricing strategies in the era of digitalisation and the perceived shift in consumer behaviour of youth in Poland. J. Int. Stud. 2019, 12, 74-91. [CrossRef] 
17. Bilan, Y.; Gavurova, B.; Stanislaw, G.; Tkacova, A. The Composite Coincident Indicator (CCI) for business cycles. Acta Polytech. Hung. 2017, 14, 71-90. [CrossRef]

18. Pekerşen, Y.; Tugay, O. Professional satisfaction as a key factor in employee retention: A case of the service sector. J. Tour. Serv. 2020, 20,1-27. [CrossRef]

19. Prause, G.; Atari, S. On sustainable production networks for Industry 4. Entrep. Sustain. Issues 2017, 4, 421-431. [CrossRef]

20. Bales, G.L.; Das, J.; Tsugawa, J.; Linke, B.; Kong, Z.D. Digitalization of human operations in the age of cyber manufacturing: Sensorimotor analysis of manual grinding performance. J. Manuf. Sci. Eng. Trans. ASME 2017, 139, 101011. [CrossRef]

21. Boneva, M. Challenges Related to the Digital Transformation of Business Companies. In Proceedings of the Innovation Management, Entrepreneurship and Sustainability (IMES 2018), Prague, Czechia, 31 May-1 June 2018; pp. 101-114.

22. Vorontsova, A.; Vasylieva, T.; Bilan, Y.; Ostasz, G.; Mayboroda, T. The influence of state regulation of education for achieving the sustainable development goals: Case study of central and Eastern European countries. Adm. Manag. Public 2020, 34, 6-26. [CrossRef]

23. Behun, M.; Gavurova, B.; Tkacova, A.; Kotaskova, A. The impact of the manufacturing industry on the economic cycle of European Union countries. J. Compet. 2018, 10, 23-39. [CrossRef]

24. Nosková, M.; Peráček, T. Termination of employment in the Slovak republic as a key issue of HR management. Cent. Eur. J. Labour Law Pers. Manag. 2019, 2, 44-59. [CrossRef]

25. Messeni Petruzzelli, A.; Albino, V.; Carbonara, N.; Rotolo, D. Leveraging learning behavior and network structure to improve knowledge gatekeepers' performance. J. Knowl. Manag. 2010, 14, 635-658. [CrossRef]

26. Santoro, G.; Bresciani, S.; Papa, A. Collaborative modes with cultural and creative industries and innovation performance: The moderating role of heterogeneous sources of knowledge and absorptive capacity. Technovation 2020, 92-93, 102040. [CrossRef]

27. Bilan, Y.; Mishchuk, H.; Samoliuk, N.; Grishnova, O. ICT and economic growth: Links and possibilities of engaging. Intellect. Econ. 2019, 13, 93-104. [CrossRef]

28. World Economic Forum. Futures of Jobs. Employment, Skills and Workforce Strategy for the Fourth Industrial Revolution. 2016. Available online: http://reports.weforum.org/future-of-jobs-2016 (accessed on 17 September 2016).

29. Del Giudice, M.; Della Peruta, M.R. The impact of IT-based knowledge management systems on internal venturing and innovation: A structural equation modeling approach to corporate performance. J. Knowl. Manag. 2016, 20, 484-498. [CrossRef]

30. Cillo, V.; Garcia-Perez, A.; Del Giudice, M.; Vicentini, F. Blue-collar workers, career success and innovation in manufacturing. Career Dev. Int. 2019, 24, 529-544. [CrossRef]

31. Shams, R.; Vrontis, D.; Belyaeva, Z.; Ferraris, A.; Czinkota, M.R. Strategic agility in international business: A conceptual framework for "agile" multinationals. J. Int. Manag. 2020, 100737. [CrossRef]

32. World Bank. World Development Indicators, 2016-2018. Available online: http://wdi.worldbank.org/table/2.5 (accessed on 23 June 2020).

33. World Economic Forum. The Fourth Industrial Revolution and Its Transformational Impact. In Proceedings of the Annual Meeting of the New Champions 2016, Tianjin, China, 26-28 June 2016; Available online: https://www.weforum.org/events/annual-meeting-of-the-new-champions-2016/sessions/the-fourthindustrialrevolution-and-its-transformational-impact (accessed on 7 September 2016).

34. Hotelling, H. Relations between two sets of variates. Biometrika 1936, 28, 3-4, 321-377. [CrossRef]

35. Sherry, A.; Henson, R.K. Conducting and interpreting Canonical Correlation Analysis in personality research: A user-friendly primer. J. Personal. Assess. 2005, 84, 37-48. [CrossRef] [PubMed]

36. Georgescu, I.; Kinnunen, J. Well-being and economic freedoms in OECD. In Rethinking Social Action. Core Values in Practice; Editura Lumen: Iasi, Romania, 2019; pp. 108-125.

37. Penha Cysne, R. On the positive correlations between income inequality and unemployment. Rev. Econ. Stat. 2009, 91, 218-226. [CrossRef]

38. Dattalo, P.V. A demonstration of canonical correlation analysis with orthogonal rotation to facilitate interpretation. In Social Work Publications; Virginia Commonwealth University: Richmond, Virginia, 2014.

39. Gonzales, I.; Déjean, S.; Martin, I.G.P.; Baccini, A. CCA: An R package to extend canonical correlation analysis. J. Stat. Softw. 2007, 23, 1-14. [CrossRef] 
40. Nardo, M.; Saisana, M.; Saltelli, A.; Tarantola, S.; Hoffmann, A.; Giovannini, E. Handbook on Constructing Composite Indicators: Methodology and User Guide; OECD Publishing: Paris, France, 2008.

41. OECD. Compendium of OECD Well-Being Indicators. OECD Better Life Initiative. Available online: http://www.oecd.org/std/47917288.pdf (accessed on 7 May 2020).

42. Jolliffe, I.T. Principal Component Analysis; Springer: New York, NY, USA, 1986.

43. Cleff, T. Desckriptive Statistik und Explorative Dateanalyse; Springer: Cham, Switzerland, 2015; pp. $217-234$.

44. Zhang, L.; Chen, S. China's Digital Economy: Opportunities and Risks; IMF: Washington, DC, USA, 2019.

45. Ambrosio, F.; Rückert, D.; Weiss, C. Who is prepared for the new digital age? In Evidence from the EIB Investment Survey; European Investment Bank: Kirchberg, Luxembourg, 2020.

46. Linkov, I.; Trump, B.D.; Poinsatte-Jones, K.; Marie-Valentine, F. Governance Strategies for a Sustainable Digital World. Sustainability 2018, 10, 440. [CrossRef]

47. Chakravorti, B.; Chaturvedi, R.S. Research: How Technology could promote growth in 6 African Countries. In Harvard Business Review; Harvard Business Publishing: Brighton, MA, USA, 2019.

48. Rastegar, A.A.; Mahbanooei, B.; Ghasemi, R. Canonical Correlation Analysis between Technological Readiness and Labour Market Efficiency: A Secondary Analysis of Countries Global Competitiveness in 2011-2012. In Proceedings of the 13th International Conference on Econometrics, Operations Research and Statistics (ICEOS 2012), Northern Cyprus, Turkey, 24-26 May 2012.

49. Sima, V.; Gheorghe, I.G.; Subić, J.; Nancu, D. Influences of the Industry 4.0 revolution on the human capital development and consumer behaviour: A systematic review. Sustainability 2020, 12, 4035. [CrossRef]

50. Rosin, A.F.; Proksch, D.; Stubner, S.; Pinkwart, A. Digital new ventures: assessing the benefits of digitalization in entrepeneurship. J. Small Bus. Strategy 2020, 30, 59-71.

51. Jandrić, M.; Randelović, S. Adaptability of the work force in Europe-changing skills in the digital era. $Z b$. Rad. Ekon. Fak. Rijeci 2018, 36, 757-776. [CrossRef]

52. Shkarlet, S.; Oliychenko, I.; Dubyna, M.; Ditkovska, M.; Zhovtok, V. Comparative analysis of best practices in e-government implementation and use of this experience by developing countries. Adm. Manag. Public 2020, 34, 118-136. [CrossRef]

53. Batkovskiy, A.M.; Leonov, A.V.; Pronin, A.Y.; Semenova, E.G.; Fomina, A.V.; Balashov, V.M. Sustainable development of Industry 4.0: The case of high-tech products system design. Entrep. Sustain. Issues 2019, 6, 1823-1838. [CrossRef]

54. Pogodina, T.V.; Aleksakhina, V.G.; Burenin, V.A.; Polianova, T.N.; Yunusov, L.A. Towards the innovation-focused industry development in a climate of digitalization: The case of Russia. Entrep. Sustain. Issues 2019, 6, 1897-1906. [CrossRef]

55. Vlasov, A.I.; Shakhnov, V.A.; Filin, S.S.; Krivoshein, A.I. Sustainable energy systems in the digital economy: Concept of smart machines. Entrep. Sustain. Issues 2019, 6, 1975-1986. [CrossRef]

56. Adeniran, A.O.; Hamid, M.J.; Noor, H.M. Impact of information technology on strategic management in the banking sector of Iraq. Insights Reg. Dev. 2020, 2, 592-601. [CrossRef]

57. Laužikas, M.; Miliūtè, A. Human resource management effects on sustainability of high-tech companies: What Lithuania and Korea can learn from each other. Insights Reg. Dev. 2020, 2, 562-579. [CrossRef]

58. Plèta, T.; Tvaronavičienè, M.; Della Casa, S. Cyber effect and security management aspects in critical energy infrastructures. Insights Reg. Dev. 2020, 2, 538-548. [CrossRef]

(C) 2020 by the authors. Licensee MDPI, Basel, Switzerland. This article is an open access article distributed under the terms and conditions of the Creative Commons Attribution (CC BY) license (http://creativecommons.org/licenses/by/4.0/). 